TI 2015-117/VIII

Tinbergen Institute Discussion Paper

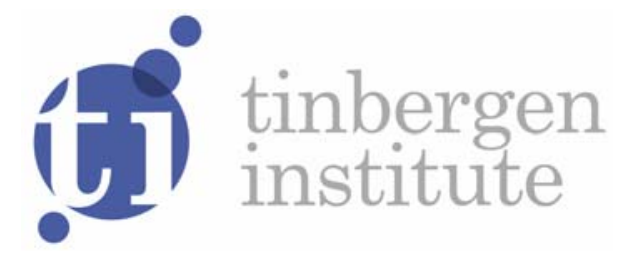

\title{
The External Cruising Costs of Parking
}

Eren Incil

Jos van Ommeren²

Martijn Kobus 3

I Sabanci University, Turkey;

2 Faculty of Economics and Business Administration, VU University Amsterdam, and Tinbergen Institute, the Netherlands;

3 MuConsult, the Netherlands. 
Tinbergen Institute is the graduate school and research institute in economics of Erasmus University Rotterdam, the University of Amsterdam and VU University Amsterdam.

More TI discussion papers can be downloaded at http://www.tinbergen.nl

Tinbergen Institute has two locations:

Tinbergen Institute Amsterdam

Gustav Mahlerplein 117

1082 MS Amsterdam

The Netherlands

Tel.: +31(0)20525 1600

Tinbergen Institute Rotterdam

Burg. Oudlaan 50

3062 PA Rotterdam

The Netherlands

Tel.: +31(0)10 4088900

Fax: +31(0)10 4089031 


\title{
The External Cruising Costs of Parking ${ }^{*}$
}

\author{
Eren $\operatorname{Inci}^{\dagger}$, Jos van Ommeren ${ }^{\ddagger}$, and Martijn Kobus ${ }^{\S}$
}

13 October 2015

\begin{abstract}
Existing work emphasizes the importance of traffic congestion externalities, but typically ignores cruising-for-parking externalities. We introduce a novel methodology to estimate the marginal external cruising costs of parking. The level of cruising is identified by examining to what extent the car inflow rate into the parking location falls with parking occupancy level. For a commercial street in Istanbul, we demonstrate that a marginal car parking for one hour induces 3.6 other cars to cruise for parking. This translates into an external cruising cost that far exceeds the external traffic congestion cost created by the trip.
\end{abstract}

Keywords: administrative parking data; cruising for parking; external costs of parking; parking fee; parking occupancy rate

JEL classification: D62; H23; L91; R41; R48

\footnotetext{
* This paper is screened by ISPARK to ensure that no confidential information is revealed. The authors would like to thank ISPARK for providing the data. Inci would like to acknowledge financial support from the Turkish Academy of Sciences (Outstanding Young Scientist Award, TUBA-GEBIP) and the recognition by the Science Academy (Turkey) via its Young Scientist Award (BAGEP). All remaining errors are the authors' responsibility.

${ }^{\dagger}$ Tel.: 90-216-483-9340; fax: 90-216-483-9250. Address: Sabanci University, Faculty of Arts and Social Sciences, Orhanli/Tuzla 34956 Istanbul, TURKEY. E-mail address: ereninci@sabanciuniv.edu.

${ }^{\ddagger}$ Tel.: 31-20-5986096. Address: VU University, FEWEB, De Boelelaan, 1081 HV Amsterdam, the NETHERLANDS; E-mail address: jos.van.ommeren@vu.nl. Jos van Ommeren is a fellow of the Tinbergen Institute, Amsterdam.

${ }^{\S}$ Tel.: 31-33-4655054. Address: MuConsult, Utrechtseweg 24, 3811 NB Amersfoort, the NETHERLANDS.E-mail address: m.kobus@muconsult.nl.
} 


\section{Introduction}

Delays in car travel time due to traffic congestion have resulted in many studies that estimate the marginal external congestion cost of car travel. This external cost is essential in deriving optimal road prices and has been found to be substantial (see, e.g., Small and Verhoef, 2007; Parry et al., 2007). ${ }^{1}$ Analogously, the derivation of optimal parking fees requires an estimation of the marginal external cruising costs of parking (i.e., the costs that an additional parked car imposes on other cars by inducing them to search for parking). Although many studies have shown that cruising-for-parking time is substantial (see, e.g., Salomon, 1984; Shoup, 2005, 2006, 2007; Belloche, 2015), essentially no information has been tracked about the size of the implied marginal external cruising cost. The current paper aims to fill this gap by introducing a novel methodology. We apply our methodology to a busy commercial street in Istanbul, although it can be applied to any city or town that collects administrative parking data. Our main finding is that the external cruising cost of one marginal shopping trip is substantial and even exceeds the external cost of traffic congestion generated by this trip.

When curbside parking is underpriced, its demand exceeds supply, and cruising for parking emerges to ration demand. For example, in US cities, curbside parking fees may be as low as one dollar per hour, which are sure to be less than the hourly costs since nearby parking garages commonly charge much higher fees. This well-known point has attracted long-standing attention in the literature (see, e.g., Shoup, 1999, 2005, 2006, 2007; Anderson and de Palma,

\footnotetext{
${ }^{1}$ In the urban and transportation economics literatures, externalities and policies to correct for them, by pricing or other policy instruments, play an important role. For example, to be able to examine the welfare effects of transit subsidies, it is important to understand the effect of public transit supply on car congestion externalities (Parry and Small, 2009; Anderson, 2014; Basso and Silva, 2014) and on environmental externalities (Chen and Whalley, 2012). It is also crucial to know the effect of the supply of road infrastructure on car congestion externalities (Duranton and Turner, 2011) and of taxation of car weight on reducing car accident externalities (White, 2004; Anderson and Auffhammer, 2014).
} 
2004, 2007; Arnott and Inci, 2006, 2010; Calthrop and Proost, 2006; Arnott and Rowse, 2009; Arnott et al., 2015; Inci and Lindsey, 2015). Cruising for parking is one of the major sources of traffic congestion in many cities around the world. For example, 45 percent of traffic on $7^{\text {th }}$ Avenue in Brooklyn, New York, comprises vehicles cruising for parking (Transportation Alternatives, 2007). In the SoHo District of Manhattan, the share of cruising cars is about 28 percent (Schaller Consulting, 2006). Although these numbers may seem to be shockingly high, they are in fact quite representative. Shoup (2005, 2006, 2007) reports that, in eleven past studies covering predominantly US cities, the average of the share of cruising traffic is 30 percent and the average cruising time is eight minutes. In contrast, in cities where the curbside parking fee is equal to, or even slightly exceeds, the price of commercial garage parking, as is common in North European countries (e.g., Denmark, the Netherlands, Belgium), cruising time is around 30 seconds, and hence essentially absent (van Ommeren et al., 2012). Thus, cruising is really a pricing issue that can easily be dealt with by implementing better parking policies.

In this paper, we focus on the generation process of cars cruising for parking on busy downtown streets. There are three groups of cars on such streets: cars in transit from one point to another, cars cruising for parking, and cars that are parked. We develop a novel methodology to estimate how many extra cars cruise for parking because an additional car has been parked, which allows us to estimate the marginal external cruising costs of parking. To estimate the number of cars cruising for parking generated by a marginal car parking on the curb, we use information about two key variables, the inflow rate into parking at a particular parking location (i.e., the number of cars that park per unit time) and the occupancy level of the parking location (i.e., the number of parked cars). These two variables can easily be inferred from administrative parking data collected by many cities and towns. The level of cruising for parking is then 
identified by examining to what extent the inflow rate falls with the occupancy level. We measure occupancy level and inflow rate per minute. We empirically demonstrate that the inflow rate sharply decreases (almost linearly) as the occupancy rate exceeds 85 percent. $^{2}$ Under certain reasonable assumptions, this reduction in the inflow rate can be interpreted as an exact measure of the number of cars that are cruising.

We make two key identifying assumptions. The first is that the occupancy level has no direct effect on the inflow rate in the absence of cruising for parking, conditional on control variables. The second assumption is that drivers do not know the exact occupancy level when they are approaching the parking location; they only have an expectation of the occupancy level for the next 15 minutes, and thus make their decisions to cruise for parking at this location based on this expectation. This informational assumption relies on rational expectations and is consistent with a range of papers, including Anderson and de Palma (2004, 2007). We make this assumption to ensure that our measure of cruising for parking does not capture reductions in parking demand by drivers who shy away from parking search because of prohibitively high expected occupancy levels (e.g., they could cancel their travel or come by bus). Such reductions are unrelated to the external costs due to parking search but rather stem from the rivalrous nature of the "good" of parking. ${ }^{3}$ One of our main control variables is the drivers' expected occupancy level during the 15-minute interval of their arrival. Although this expected level is

\footnotetext{
${ }^{2}$ This occupancy rate happens to coincide with the recommended occupancy rate proposed by Shoup (2005). To what extent such an occupancy rate applies to other locations is unknown since simulation models show that the optimality of occupancy rates is location dependent (Levy et al., 2012).

${ }^{3}$ To be precise, if a driver occupies a parking space, that space becomes unavailable to other drivers. Some of those drivers shy away from parking because they expect prohibitively high occupancy levels while the rest still drive to the neighborhood and search for parking. The latter group incurs external costs due to their parking search, on which we concentrate. For the former group, the problem is just the rivalrous nature of parking - for that matter for any good that is at least partially a private good. The analogy would be if a person eats an apple, that apple becomes unavailable to others.
} 
not observed, we are able to control for the expected occupancy level by including 15-minute-interval fixed effects. Given this setup, we identify the marginal external cruising cost of parking: the costs that an additional parked car imposes on other drivers by inducing them to search for parking, a so-called search externality. ${ }^{4}$

Arguably, the occupancy level may not be fully exogenous with respect to the inflow rate even after controlling for 15-minute-interval fixed effects. To test for endogeneity of the occupancy level, we also adopt an instrumental variable approach. In this approach, we use the fact that parking fees jump discretely with respect to parking duration at hourly increments. These discrete price jumps affect drivers' parking duration, and thereby the outflow of parked cars and ultimately the occupancy level. ${ }^{5}$ Hence, to instrument for the occupancy level at a given time period, we use the (15-minute lagged) share of parked cars who face a discrete jump in parking fees.

We apply our methodology to a parking location on a commercial street of Istanbul that contains 23 parking spaces with a very high average parking occupancy. We show that when a (marginal) car driver parks for one additional hour, the hourly inflow rate is reduced by about 3.6 cars, implying that during this hour 3.6 other cars attempt to park but are denied access. Our back-of-theenvelope calculations reveal that the marginal external cruising cost of parking is between 0.4 and 2.4 Liras per hour of parking, whereas our preferred calculation points at 1.2 Liras per hour of parking. The external cruising costs due to high occupancy levels are thus quite substantial. For example, in our preferred calculation, the marginal external cruising cost of parking is equivalent to about 15 percent of the average wage rate in Istanbul or about 60 percent of the

\footnotetext{
${ }^{4}$ This type of externality is called a "congestion" externality in the labor economics literature (Pissarides, 2000), which is a somewhat confusing terminology to use in a transportation context.

${ }^{5}$ We provide additional empirical evidence based on micro-level data that drivers are more likely to leave the parking location just before the parking fee of the next hour applies.
} 
marginal parking fee that a driver faces after an hour of parking. ${ }^{6}$ Thus, underpriced parking creates substantial welfare losses, which can easily be avoided by increasing parking fees. ${ }^{7}$

This paper is not the first to provide estimates related to cruising for parking. Past work concentrates mainly on the average level of cruising-forparking time. Information about cruising time usually comes from precise measurements within small areas obtained by manual or automatic counting, precise measurements relying on experimental approach in which drivers are asked to park in certain areas, or estimates deduced from surveys. These approaches are excellent in getting precise numbers about average cruising time, but they are too expensive to be undertaken at a large scale. More fundamentally, they are not indicative of the marginal external cruising cost of parking. Our approach complements them by estimating this external cost using administrative parking data for Istanbul.

Our econometric methodology is useful in the sense that it enables researchers and policy makers to quantify by how much parking fees must be increased minimally in order to increase welfare. The methodology is straightforward and relies only on administrative parking data, which are regularly collected on a large scale by many cities and towns throughout the world. ${ }^{8}$ Thus, our methodology can be easily and economically applied by parking authorities to examine whether current parking fees in a given city are efficient.

\footnotetext{
${ }^{6}$ For comparison, we note that 15 percent of the hourly wage in the US corresponds to about 2.7 dollars per hour, given that the net hourly wage is around 18 dollars in 2013.

${ }^{7}$ This welfare loss is still an underestimate for at least two reasons. First, there is also the external cost that cars cruising for parking impose on each other and cars in transit, which magnifies traffic congestion, emissions, etc. Second, as a result of underpriced parking, a driver with a lower willingness to pay may be able to take a parking space at the expense of other drivers who have higher willingness to pay.

${ }^{8}$ Although administrative parking data have existed for a long time, they have been utilized in research only very recently (see, e.g., Kelly and Clinch, 2009; Bakis et al., 2015).
} 
The paper is organized as follows. Section 2 discusses the identification strategy. Section 3 describes the data and provides some descriptive statistics. Section 4 derives the empirical results, and Section 5 concludes.

\section{Identification strategy}

Our aim is to estimate the marginal external cruising costs of parking. We have in mind the standard parking cruising model à la Anderson and de Palma (2004). Consider first a case in which drivers park for a fixed amount of time. The probability of finding a vacant parking space depends negatively on the occupancy level. A driver continues to cruise for parking until he finds a vacant parking space. The full price of parking for him is equal to the parking fee plus the value of his time lost during cruising. There is always some cruising in any steady state in this model. Drivers ignore the cruising externality that they impose on each other. A sufficiently high parking fee would mitigate this externality by decreasing trip demand and therefore the occupancy level at the location. The optimal parking fee per unit of time is then equal to the marginal external cost of parking. Now relax the steady-state assumption and assume that there is a distribution of parking durations known by all drivers. Hence, drivers know the expected occupancy rate, but not the actual one at the time of their arrival. Given this assumption, parking demand does not vary over time, because drivers' decision to travel to the parking location depends on the expected occupancy rate. However, the cruising time varies over time because of the differences between the actual and the expected occupancy rate.

Our empirical methodology for measuring the marginal external cruising cost of parking depends crucially on the assumption that before arriving at the parking location at time $t$ (measured per minute in our application), a driver does not know the actual occupancy level for this arrival time; he only knows the expected occupancy level for a time interval $\tau$ (measured per 15 minutes in our 
application). We denote the actual occupancy level by $O_{t \tau}$, where $t$ is an exact time within the time interval $\tau$, and the expected occupancy by $O_{\tau}$. For example, in our application, we assume that before arriving at the desired location, the driver knows the expected occupancy level for each 15-minute interval (we control for these expectations by including a dummy for each interval) but does not know the exact occupancy level for a given minute within that 15-minute interval.

In certain circumstances, drivers may potentially have predictive information about the occupancy level changes within the 15-minute interval, which invalidates our identifying assumption. This is the case in the morning when occupancy levels increase sharply over time and in the evening when occupancy levels decrease over time. To rule out these possibilities, we consider only observations for the part of the day when the occupancy level is stationary (and, as it turns out, when inflow and outflow rates are stationary). In our application for Istanbul, this period is between 12:00 and 22:00.

The latent parking demand for the location under consideration at time $t$, denoted by $D_{t \tau}$, is a function of parking fees and the expected occupancy level, $O_{\tau}$. Once drivers arrive at the parking location, they observe the actual parking occupancy level, $O_{t \tau}$. The latent demand is unobserved, but we do observe the inflow rate into parking at time $t$, which is denoted by $F_{t \tau}$. When cruising for parking occurs, the inflow rate, which is nothing but the realized demand, is less than the latent parking demand. They are equal when there is no cruising for parking.

In our empirical application, we estimate the inflow rate $F_{t \tau}$ as a function of actual occupancy level $O_{t \tau}$ while controlling for the expected occupancy level $O_{\tau}$ through time-interval fixed effects. Hence, we control for the exact 15-minute interval of each observation (e.g., between 14:00 and 15:00 on January 10, 2011), and therefore control for all unobserved variables within the time interval, 
including the average occupancy level. Assuming a linear relationship between the inflow rate $F_{t \tau}$ and the occupancy level $O_{t \tau}$, we estimate

$$
F_{t \tau}=\alpha+\beta O_{t \tau}+\gamma T_{\tau}+\varepsilon_{t \tau},
$$

where $T_{\tau}$ refers to the time-interval fixed effects, $\alpha, \beta$, and $\gamma$ are coefficients to be estimated, and $\varepsilon_{t \tau}$ is the random-error component.

By including time-interval fixed effects, we avoid the potential endogeneity problem that the inflow rate $F_{t \tau}$ depends on the occupancy level $O_{t \tau}$ because occupancy level differences within 15-minute time interval are likely to be random for drivers after controlling for the expected occupancy for this time interval. Given these time-interval fixed effects, the coefficient $\beta$ can be interpreted as the marginal effect of occupancy on the number of cars cruising.

Equation (1) assumes that the effect of occupancy level on the inflow rate is linear. In general, this assumption is unlikely to hold for various reasons. First, the probability of finding a vacant parking space is not a linear function of the occupancy level (Anderson and de Palma, 2004). Second, cruising for parking mainly occurs when curbside parking is saturated (i.e., completely full). Therefore, the occupancy level should have a discontinuous impact on the inflow rate rather than a continuous one, and this is not captured by equation (1). ${ }^{9}$ To capture nonlinear effects, including discontinuous ones, we estimate the effect of occupancy level on the inflow rate in the most flexible way possible by including a dummy indicator of the exact number of parked cars. Consequently, we estimate:

$$
F_{t \tau}=\alpha+\sum \beta_{O} I\left(O_{t}\right)+\gamma T_{\tau}+\varepsilon_{t \tau},
$$

\footnotetext{
${ }^{9}$ In our context of a commercial street in Istanbul, this discontinuity may not exist because drivers cannot easily see whether all parking spaces are vacant. Furthermore, some drivers may observe a vacant parking space but cannot park there during the one-minute period of observation because, say, it is on the other side of the street or it can be reached only after passing traffic lights, by which time it has been taken.
} 
where $I\left(O_{t}\right)$ denotes a dummy indicator of the exact number of parked cars, $\beta_{O}$ captures the effect of $I\left(O_{t}\right)$, and $\sum$ sums over $O$. We call this the flexible specification. We shall show that the linear specification in equation (1) holds only when the occupancy level exceeds 85 percent of the parking capacity.

Although we include 15-minute time-interval fixed effects, there may still be a small endogeneity problem because it is possible that parking demand is (positively or negatively) autocorrelated within the 15-minute interval. This could potentially create problems because the occupancy level during a particular minute depends on the level of parking demand in the previous minutes. We test for such an endogeneity problem by using an instrumental variable approach that we apply using equation (1) when the occupancy level exceeds 85 percent of the parking capacity. In our empirical application, most drivers pay for parking per each hour. Thus, drivers have high incentives to leave the parking space right before the parking fee of the next hour applies.

Our instrumental variable is the share of drivers who face a discrete price jump at time $t-1$ (of all drivers who have parked before time $t$ ) to instrument for the occupancy level at time $t$. This instrumental variable is subject to (random) variation, and influences the occupancy level at time $t$ by inducing drivers to leave just before time $t$. The idea is that discrete jumps in parking fees induce drivers to terminate parking right before the jump. The identifying assumption here is that the share of the drivers who have parked before time $t$ is independent of the inflow rate at time $t$.

\section{Data and descriptive statistics}

Our data on inflow rates and occupancy levels are derived from micro-level parking transactions that took place at a curbside parking location on Tesvikiye Street in Nisantasi, Istanbul. We chose this location among hundreds of other locations in Istanbul because it has high average occupancy levels and thus 
cruising is likely to be excessive. Moreover, this street is one-way and thus if one misses a vacant parking space it is hard to come back to it, although not impossible. This location is a busy district with lots of luxurious shopping stores. Curbside parking is managed by a municipal parking operator called ISPARK, which provided the administrative parking data. There is no parking information system at this location, or as a matter of fact anywhere else in the city. Thus, drivers have no prior information on parking occupancy. They can only find out on the spot whether there is a vacant parking space. Parking fees are collected by parking attendants who record the transactions using an electronic hand terminal.

There are formally 23 designated parking spaces at this parking location. ${ }^{10}$ Our data include 191,771 micro-level parking transactions covering the period between January 1, 2010 and March 31, 2013. ${ }^{11}$ The data provide information on (i) exact times of inflow and outflow and (ii) parking fee payment. We derive the parking durations using these variables. As may be expected for commercial streets, parking durations are quite short: the average parking duration is almost 2 hours (119 minutes), whereas the median parking duration is 72 minutes. The Tesvikiye Mosque is on this street, which is well known for events of national importance, such as funerals of famous people. Thus, the street is sometimes closed to make room for double or even triple parking. These kinds of events are rare, however.

Using micro-level transactions, we calculate our aggregate variables of the inflow and outflow rates per one-minute intervals. ${ }^{12}$ When computing occupancy

\footnotetext{
${ }^{10}$ There are about 315 paid curbside parking spaces within a perimeter of 250 meters, including those in the parking location that we are concentrating on.

${ }^{11}$ The transaction data are very accurate. Parking transactions are registered using hand terminals. We found very limited evidence of miscoded parking transactions. We observed only 33 instances where the registered time of inflow is after the registered time of outflow (which we exclude from the analysis).

${ }^{12}$ As a robustness check, we also examined results presented in this paper with two-minute and five-minute intervals. The results are very similar to the ones reported here and can be provided on request.
} 
levels, also calculated per minute, we assume that each vehicle (including motorbikes and buses) occupies exactly one parking space. ${ }^{13}$ The occupancy level is not directly observed, but given information on inflow and outflow rates before time $t$, we can calculate the occupancy level at $t$. In the current paper, we calculate the occupancy level based on the inflow and outflow rates of the previous seven days. ${ }^{14}$

We make several data selections by excluding certain days. First, we exclude observations on Sundays. Second, we exclude 55 days with extreme overcapacity, defined as occupancy levels exceeding formal capacity by more than five cars, as this indicates severe double parking. ${ }^{15}$ Severe double parking reduces traffic flow and therefore the inflow rate into parking even in the absence of cruising, and this can create a spurious relationship between occupancy level and inflow rate. Third, we exclude nine days during which the parking location was almost completely empty, defined as occupancy levels with fewer than five cars (it is likely that nearby streets were closed during these days, so the parking location could not be reached). Fourth, we exclude the first seven days of 2010, because for these days we cannot construct the occupancy level as we have no information about inflow and outflow rates before 2010. After these data selections, we end up with observations for 946 days.

\footnotetext{
${ }^{13}$ The occupancy levels are therefore prone to some measurement error because of differences in vehicle sizes: motorbikes occupy less than one regular parking space while large-sized vehicles occupy more than one regular parking space. However, the measurement error is negligible, because more than 98 percent of the transactions refer to cars, whereas only 1.6 percent refer to large-sized vehicles such as buses and minibuses and less than 0.1 percent refer to motorbikes. Formally, motorbikes are supposed to park in regular parking spaces, and not on the sidewalk. Two motorbikes fit into one single parking place.

${ }^{14}$ Note that although occupancy levels are calculated quite accurately, the occupancy ratedefined as occupancy level divided by the parking capacity-is prone to measurement error because of double parking. Hence, in our analysis, we use occupancy level rather than the occupancy rate.

${ }^{15}$ This extreme overcapacity could be the result of important events taking place at nearby places, such as the Tesvikiye Mosque. During such events, streets may incidentally be closed to be used exclusively for parking.
} 
Table 1: Descriptive statistics: Mean and standard deviations

\begin{tabular}{ccccccc}
\hline Time & \multicolumn{2}{c}{$\begin{array}{c}\text { Inflow rate } \\
\text { (cars/min) }\end{array}$} & \multicolumn{2}{c}{$\begin{array}{c}\text { Outflow rate } \\
\text { (cars/min) }\end{array}$} & \multicolumn{2}{c}{$\begin{array}{c}\text { Occupancy Level } \\
\text { (cars) }\end{array}$} \\
\hline 12:00-13:00 & 0.15 & $(0.39)$ & 0.15 & $(0.40)$ & 21.07 & $(3.36)$ \\
13:00-14:00 & 0.16 & $(0.41)$ & 0.16 & $(0.42)$ & 21.06 & $(3.27)$ \\
14:00-15:00 & 0.17 & $(0.40)$ & 0.16 & $(0.41)$ & 21.29 & $(3.05)$ \\
15:00-16:00 & 0.17 & $(0.41)$ & 0.18 & $(0.44)$ & 20.94 & $(3.33)$ \\
16:00-17:00 & 0.18 & $(0.43)$ & 0.23 & $(0.70)$ & 20.24 & $(4.12)$ \\
17:00-18:00 & 0.20 & $(0.44)$ & 0.18 & $(0.56)$ & 18.18 & $(5.26)$ \\
18:00-19:00 & 0.18 & $(0.41)$ & 0.16 & $(0.42)$ & 19.79 & $(3.60)$ \\
19:00-20:00 & 0.17 & $(0.40)$ & 0.16 & $(0.41)$ & 20.56 & $(3.20)$ \\
20:00-21:00 & 0.16 & $(0.39)$ & 0.16 & $(0.41)$ & 20.70 & $(3.30)$ \\
21:00-22:00 & 0.15 & $(0.38)$ & 0.17 & $(0.42)$ & 20.07 & $(3.75)$ \\
\hline
\end{tabular}

Notes: Standard deviations are in parentheses. The formal parking capacity is 23 cars.

We also make data selections based on the hour of the day. We include observations for a time interval of 10 hours during the day, between 12:00 and 22:00. This implies that we have 567,600 minutes of observations (946 days $\times 10$ hours $\times 60$ minutes). Table 1 provides descriptive statistics (means and standard deviations) of the inflow and outflow rates and occupancy levels per hour of the day. For each hour of the day, inflow and outflow rates are mostly around 0.17 cars per minute. ${ }^{16}$ The occupancy is typically very high and there is little variation in occupancy levels during the day.

Figure 1 provides a histogram of the occupancy levels at the parking location. The number of occupied parking spaces is usually slightly less than 23, which is the formal parking capacity. Often times, the parking location is quite full: it seldom occurs that there are fewer than 15 occupied parking spaces. For eight percent of the time, the number of vehicles parked exceeds the formal

\footnotetext{
${ }^{16}$ The inflow rates are substantially less than one. It is only seldom that more than one car park during a one-minute interval.
} 
capacity. ${ }^{17}$ The formal capacity is, however, rarely exceeded by more than one car in our data (only one percent of our observations).

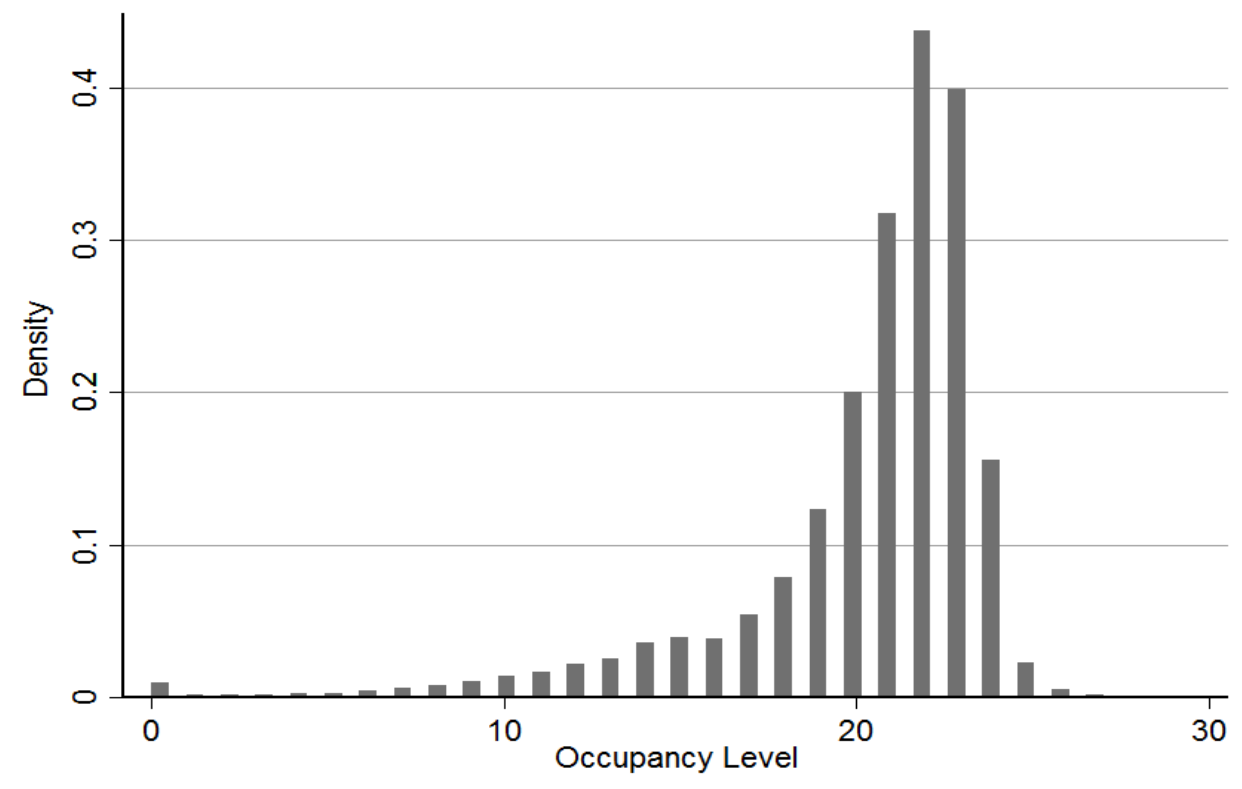

Figure 1: Histogram of occupancy level

\section{Empirical estimates}

This section reports the estimation results. Subsection 4.1 provides our main estimates based on time-interval fixed effects regressions of the inflow rates as a function of occupancy levels. Then, to deal with a potential endogeneity problem, subsection 4.2 undertakes an instrumental variable approach.

\subsection{Main results}

Using our methodology introduced in Section 2, we estimate the impact of occupancy level in terms of parked cars on the inflow rate. We first report the

\footnotetext{
${ }^{17}$ We cannot determine with certainty whether the parking location is full, because vehicles differ in size. Moreover, sometimes drivers hand in their car keys to parking attendants, which allows for “organized” double parking.
} 
regression results based on the flexible specification laid out in equation (2), where we include a dummy variable to represent the exact number of parked cars. The results are portrayed in Figure 2. The solid curve represents the point estimates of inflow rate for each occupancy level while the dotted curves represent the 95 percent confidence interval.

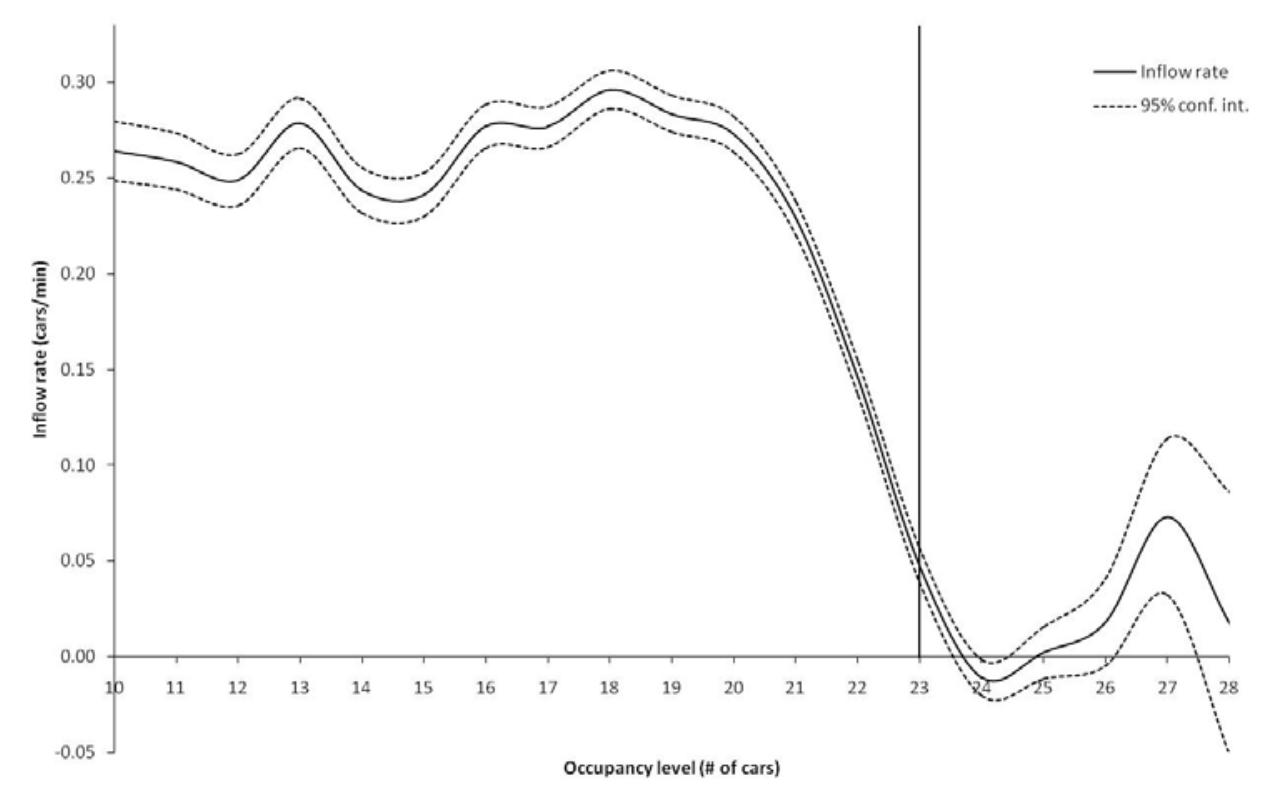

Figure 2: Inflow rate as a function of occupancy level

The results shown in the figure allow us to estimate marginal external cruising cost of parking. When the occupancy level is under 19 parked cars, about 85 percent of the formal capacity, the inflow rate hardly varies and is about 0.25 cars per minute. In this case, the external cruising cost is zero. When the occupancy level exceeds 19 parked cars, as it is approaching the formal parking capacity of 23 cars, a sharp (and almost linear) decrease occurs in the inflow rate. The inflow rate is essentially zero when the parking location is entirely full. 
Concentrate on the size of the change in the inflow rate when the sharp decrease begins, which happens around an occupancy level of 19 cars. ${ }^{18}$ At this point, if the occupancy level increases from 19 to 20 cars, the inflow rate decreases by 0.01 cars per minute. An additional car from 20 to 21 parked cars decreases the inflow rate by 0.04 cars per minute. If occupancy further increases by one car, the inflow rate decreases by 0.08 cars per minute. Yet another increase in the occupancy level at that point decreases the inflow rate by 0.10 cars per minute. Finally, exceeding the full formal occupancy of 23 cars by one more car decreases the inflow rate by 0.06 cars per minute. Therefore, close to the formal parking capacity, the average decrease in the inflow rate is about 0.06 cars per minute for each additional parked car. Hence, the decrease in the hourly inflow rate is 3.6 cars when the occupancy level increases by one car. In other words, for each additional car parked for an hour, 3.6 drivers aim to park at this location but cannot find a parking space.

Based on this estimate, we now provide some back-of-the-envelope calculations of the marginal external cost of cruising. Although we estimate that 3.6 cars get into parking search in response to one additional car parking on the curb, we do not know how they exactly search for a parking space. Following Anderson and de Palma (2004), we assume that drivers employ a random sampling approach with replacement in a stationary environment. We further assume that the parking condition at the nearby locations are similar, which is very reasonable for Nisantasi, and thus we can limit ourselves with the parking location we concentrate on.

A driver learns the occupancy level once he arrives at the location. If there are $x$ parked cars, then with random sampling, the particular parking space that he examines is empty with probability $q(x)=(23-x) / 23$. As calculated in Footnote 9

\footnotetext{
${ }^{18}$ It is not completely clear whether cruising starts at 19 or 20 parked cars. Here, we assume that it starts at 19 parked cars, but the results for 20 parked cars are essentially the same.
} 
in Anderson and de Palma (2004), this means that the expected number of parking spaces that a driver searches for before finding a vacant parking space is $1 / q(x)$. Figure 1 reports how often each occupancy level occurs in the parking location. Denoting the frequency of occupancy level $x$ by $n(x)$, we calculate the expected number of parking spots that a driver examines before finding a vacant parking space, which equals $\sum n(x) / q(x)$, where the summation sign sums over $x$. In theory, $q$ is zero when there are no vacant parking spaces, implying that the driver needs to search for an infinite number of parking spaces. As our data show, in practice, the occupancy level can be equal to or even exceed the formal capacity for a limited time period, so the number of parking spaces to be examined is finite, and we have to constrain search time at and beyond this capacity. In our baseline estimations, we assume that the number of parking spots that a driver examines doubles if occupancy increases from 22 to 23 cars, i.e., $q(23)=1 / 46$, and it stays the same for all occupancy levels beyond 23 cars. Thus, we treat all capacity levels beyond the formal capacity in the same way. ${ }^{19}$ Given these assumptions, we find that a driver is expected to examine 21.6 parking spaces. ${ }^{20}$

Given that we estimate 3.6 drivers to be searching for parking, in total 77.8 cars will be shut out during a marginal hour of parking. Assuming that there is a parking space at every 10 meters after taking into account the spaces due to intersections, fire hydrants, no parking zones, etc., and that a typical driver cruises for parking at an average speed of $11 \mathrm{~km} / \mathrm{h}$, a driver can examine 1,100 parking spaces in an hour. Thus, 77.8 cars will be losing about 4.2 minutes in total as a result of their parking search at this parking location. We assume that the hourly

\footnotetext{
${ }^{19}$ It may be more reasonable to assume that the number of parking spaces examined grows much faster when there are no parking spaces once the driver arrives at the parking location. To account for that, we also worked out the calculations with $q(23)=1 / 230$ at the formal capacity and for higher occupancy levels. In that case, a driver is expected to examine 74.4 parking spaces, suggesting that our assumptions on $q(23)$ are very conservative.

${ }^{20}$ If we had assumed, in line with the results in Figure 2, that there was no cruising below occupancy levels of 19 cars, we would get 21.0 cars, rather than 21.6. Thus, results remain essentially the same. They do not change much because low occupancy levels occur seldom.
} 
value of time while driving is equal to the average hourly wage in Istanbul, which is 8.4 Liras (see TurkStat, 2013). Following the literature, the value of time while cruising is assumed to be 38 percent higher than the value of time while driving (see Abrantes and Wardman, 2011) and thus equal to 11.6 Liras. $^{21}$ Furthermore, in line with the value used in transportation planning in Istanbul, we assume that car occupancy is 1.5 persons.

Given these assumptions, the marginal external cruising cost of parking is about 1.2 Liras per hour of parking. Although we shall provide alternative estimates based on different assumptions, this is our preferred estimate. A cost of 1.2 Liras per hour of parking is substantial. For example, it is equivalent to about 60 percent of the marginal parking fee that drivers face after parking for one hour in March 2013 (see Table 2). Alternatively, it is equivalent to 15 percent of the hourly wage in Istanbul. ${ }^{22}$ Thus, underpriced parking creates substantial welfare losses.

Table 2: Parking fee schedule (March 2013)

\begin{tabular}{lccccccccc}
\hline \hline Parking duration (hours) & $<1 / 4$ & $1 / 4-1$ & $1-2$ & $2-3$ & $3-4$ & $4-5$ & $5-6$ & $6-7$ & $7-24$ \\
Parking fee (Liras) & 0 & 6 & 8 & 10 & 13 & 15 & 17 & 19 & 20
\end{tabular}

Notes: Motorbikes pay half and large-sized vehicles pay twice the fees reported here.

Another thought experiment is to compare the magnitude of the marginal external cruising cost of parking for a shopping trip with the marginal external cost of congestion created by this trip. In line with our parking duration data, we assume that the average parking duration for shopping is two hours. This implies an external cruising cost of 2.4 Liras per shopping trip. Because information about travel in Istanbul is very limited, we shall make extremely conservative

${ }^{21}$ One of the reasons that the value of time while cruising is higher than the value of time while driving is the fact that cruising increases the variation in total travel time (including cruising time), which decreases the reliability of transport supply for car drivers (Small et al., 2005).

${ }^{22}$ For comparison, 15 percent of the net hourly wage in the US corresponds to about 2.7 dollars. 
assumptions. Parry and Small (2007) estimate that the marginal external cost of car congestion is 25 cents per passenger-mile during peak hours and 6 cents during off-peak hours in Washington, DC. Assume for the moment that the marginal external travel time losses are the same for both cities. Given that Istanbul is one of the most congested cities in the world, whereas Washington is only mildly congested, this is a very conservative estimate, because time losses are thought to increase with the number of cars on a street. Assume also that the value of time while traveling in Istanbul is exactly 50 percent of that value in Washington, DC, which is again a conservative estimate because income levels in Istanbul are far less than half of those in Washington. Assuming that Istanbulians drive at peak hours 30 percent of the time, the average marginal external congestion cost of car travel in Istanbul is therefore 0.22 Liras per passengerkilometer.

As for a typical shopping activity, we assume that the shopper makes a direct round trip from home to shopping destination, which is again an underestimate because shopping activities are frequently combined with other activities. The one-way distance travelled by a car for a shopping trip in Istanbul is assumed to be $5 \mathrm{~km}$, which is comparable to distances traveled for shopping in other large congested cities (e.g., in London, the average one-way trip takes 2.9 miles, about 5.1 km, according to the England Travel Survey 2013).

Given the above assumptions, the marginal external congestion cost is 1.1 Liras for a shopping activity in Istanbul. This is far less than the half of the marginal external cruising cost of a shopping trip of 2.4 Liras. However, we emphasize once again that our assumptions are conservative. For example, estimates for Brussels suggest that the marginal external travel time losses are about four times higher than what we assumed here (De Borger and Wuyst, 2011). So, double, triple, or even quadruple our estimate of the external cost of congestion. This does not make any difference. Our exercise clearly shows that in 
any reasonable calculation for a shopping activity, externalities due to underpriced parking exceed the congestion externalities. Our point is that mitigating traffic congestion requires road pricing, which has failed to be implemented in many cities, if it has been implemented at all, while parking externalities can be addressed very easily by increasing parking fees in the city, a far less politically risky move.

To be able to offer some lower and upper bounds on our estimate of the marginal external cost of cruising, we also provide generous and conservative calculations. In our generous calculation, we assume that average cruising-forparking speed is lower and equal to $10 \mathrm{~km} / \mathrm{hr}$ and that there are parking spaces every 12 meters. Moreover, as Nisantasi is a rich neighborhood, we assume that the value of time for drivers in this neighborhood is higher. We assume that it corresponds to the net hourly wage of the $75^{\text {th }}$ percentile in Istanbul, which is about 10 Liras. If car occupancy is also higher and equal to 1.9 persons, we get an external cost of 2.4 Liras per hour of parking, which is 29 percent of the net hourly wage in Istanbul. ${ }^{23}$

In our conservative calculation, we assume that average cruising-forparking speed is higher and equal to $12 \mathrm{~km} / \mathrm{hr}$ and that there are parking spaces every 8 meters. We further assume that the value of time is much lower and equal to the half of the net hourly wage, so 4.2 Liras. Moreover, we assume that car occupancy is only 1.3 persons. In this case, the external cost is about 0.4 Liras per hour of parking, which is 5 percent of the net hourly wage in Istanbul. Consequently, it is plausible that our estimates of the marginal external cost of

\footnotetext{
${ }^{23}$ With the alternative assumption reported in Footnote 19, assuming that cruising grows pretty quickly once parking is fully saturated, our preferred calculation yields 4.2 Liras per hour of parking, which is 50 percent of the hourly wage. Our generous calculation yields 8.4 Liras per hour of parking (100 percent of the hourly wage) while our conservative calculation yields 1.3 Liras per hour of parking (16 percent of the hourly wage).
} 
cruising vary between 0.4 Liras per hour of parking and 2.4 Liras per hour of parking.

Table 3: Inflow rate

\begin{tabular}{lcc}
\hline \hline & $(1)$ & $(2)$ \\
& FE & IV with FE \\
\hline Occupancy level & -0.06810 & -0.0611 \\
& $(0.00046)$ & $(0.00306)$ \\
15 minutes fixed effects & Included & Included \\
Number of observations & 463,310 & 463,310 \\
\hline
\end{tabular}

Notes: FE: fixed effects; IV: instrumental variables. Number of occupied parking spaces is at least 19. Robust standard errors are in parentheses.

To further investigate the results, we have also estimated a linear specification using equation (1) restricting the sample to occupancy levels of at least 19 parked cars (463,310 observations). Column (1) in Table 3 reports the point estimate. In line with the flexible specification, the marginal driver who parks at this location decreases the inflow rate by about 0.068 cars per minute. Note that the standard error is only 0.0005 , hence this decrease is extremely precisely estimated (and statistically different from zero at any conventional level of significance). This specification predicts an inflow rate of essentially zero when the parking location is entirely full, which makes sense. Consequently, a linear specification seems a reasonable statistical description of the relationship between inflow rate and occupancy level when there are at least 19 cars parked. ${ }^{24}$

\footnotetext{
${ }^{24}$ We have also estimated the model without any time fixed effects. The estimates are then somewhat, but not extremely, biased and closer to zero, with a bias on the order of 25 percent. For example, the estimated impact without any time fixed effects is equal to -0.049 for the sample with an occupancy level of at least 19 cars, which must be compared with the estimate reported in column (1) of Table 3.
} 


\subsection{Instrumental Variable Estimates}

The empirical analysis presented so far is unable to deal with a potential endogeneity problem of the following sort. For example, if the inflow is blocked by heavy traffic congestion at a certain moment during a 15-minute interval, then both the inflow rate and the occupancy level may be reduced. To deal with such an endogeneity problem, we rely on an instrumental variable approach.

Our instrument is based on discrete changes in the parking fee schedules. As Table 2 documents, the regular parking fee jumps discretely at the $15^{\text {th }}$ minute, then every hour up to seven hours of parking, and finally a daily fee applies. The first 15 minutes are free. Then, parking for the first hour is 6 Liras (about 2 dollars). ${ }^{25}$ The parking fee increases discretely by 2 or 3 Liras at every hour up to seven hours, after which a daily fee of 24 Liras (about 8 dollars) applies. ${ }^{26}$ A large majority of drivers, about 94 percent, is subject to this regular pricing scheme. About 4 percent of drivers are subject to different concessionary fees. These drivers are entitled to park free for either two or three hours, after which the regular parking fee schedule applies. These are mainly the drivers who make use of the promotion of the major Turkish GSM operator Turkcell, journalists, war veterans, close relatives of martyrs, and disabled individuals. ${ }^{27}$ It seems reasonable to assume that the variation in the parked drivers who face a discrete jump in their parking fee is random with respect to the inflow rate (conditional on the 15-minute time interval fixed effects).

To motivate our instrument, we have estimated the impact of parking duration on the outflow rate using a standard Kaplan-Meier hazard rate estimator

\footnotetext{
${ }^{25}$ Officially, the parking fee is valid up to 60 minutes, but given that the first 15 minutes of parking are free, the first price jump is enforced in practice after 75 minutes of parking.

${ }^{26}$ Drivers are expected to pay for parking beforehand based on the expected parking duration that they state once they park. If they park for longer than their stated duration, they are charged the residual amount when they leave the parking space.

${ }^{27}$ About 2 percent of drivers park for free for the entire parking duration. They are mainly government officials and employees of the parking operator.
} 
based on the micro-level data (Lancaster, 1992; Wooldridge, 2002). In the Appendix, Panel (a) of Figure 3 documents the outflow rate of the drivers for whom the regular parking fee schedule applies. This figure clearly shows that the outflow rate increases just before discrete price jumps (e.g., before 75, 135 or 195 minutes of parking). As further evidence of this effect, Panel (b) concentrates on drivers who make use of a promotion of Turkcell, which gives them permission to park for free for 135 minutes. The effect is now even more pronounced. Panel (c) concentrates on journalists who can park for free for 180 minutes. For these drivers, the outflow rate more than doubles just before the discrete price jump takes effect. ${ }^{28}$ These figures clearly show that there is instrument-induced variation in the outflow rate (and therefore in the occupancy level) that can be assumed to be unrelated to the inflow rate.

We use as an instrument the share of parked cars in the previous 15minute time interval that face such a discrete parking fee increase in the next 15minute time interval. The underlying idea for this instrument is that there is exogenous variation in the outflow rate because there is variation in the share of drivers who leave the parking location before the discrete increase in the parking fee occurs. The average of this instrumental variable hardly varies over the day, supporting the assumption that this variable is random and not systematically related to the inflow rate. Given the instrument, we use 2SLS for the sample with at least 19 parked cars for which we have shown that the linearity assumption is

\footnotetext{
${ }^{28}$ Our finding that the parking duration reacts strongly to jumps in parking fees is novel. Given discrete price jumps, some drivers overconsume parking up to a certain duration (because the marginal fee for parking is zero), but because of the discrete price increase, some drivers underconsume parking (because the marginal fee exceeds the marginal cost at the jump). Discrete pricing distorts demand compared to continuous pricing (Vickrey, 1954), but reduces transaction cost of payment when drivers pay in cash. Previous studies on parking demand do not distinguish between the effect of fees on the parking probability (i.e., the extensive margin) and their effect on the parking duration (i.e., the intensive margin).
} 
reasonable. ${ }^{29}$ Our instrumental variable is strong with a $F$ value of about 20 . The results are very similar to the standard fixed effects estimates that we obtain in the previous subsections. ${ }^{30}$ As shown in column (2) of Table 3, the marginal driver who parks at this parking location decreases the inflow rate by about 0.06 cars per minute.

\section{Conclusion}

This paper introduces a novel methodology for estimating the marginal external costs to society of parking when high parking occupancy levels result in cruising for parking. In particular, our methodology estimates how many cars have attempted to park at a parking location but could not do so per unit time because of one additional car parked at this location. This methodology employs administrative parking data and thus can be easily applied to any city or town that collects such data. The outcomes can be used to determine the efficiency of parking fees at each parking location.

We apply our methodology to a parking location of 23 parking spaces on a busy commercial street in Istanbul. On this street, the occupancy levels are typically high, and in about half the time all parking spaces are occupied, which hints at substantial levels of cruising for parking. We show that when the occupancy level exceeds 19 cars (an occupancy rate of about 85 percent) the inflow rate into the parking location strongly decreases. We then demonstrate that

\footnotetext{
${ }^{29}$ In general, the procedure to use the selected sample may not generate consistent estimates when applying the instrumental variables procedure, because the selection is based on an endogenous variable, and one has to use a more complicated estimation procedure based on the whole sample that allows for nonlinearities as well as endogenous variables (see Koster et al., 2014 for an application). In the current context, given that we do not find evidence of endogeneity issues, the endogeneity created by sample selection is likely to be negligible.

${ }^{30}$ To formally test for endogeneity, we use a standard Hausman $t$-test, which is equal to 2.3. Thus, from a purely statistical point of view, exogeneity is rejected, which is not surprising because we have half a million of observations, but the difference in effect size is only 0.007 . Thus, from a substantive point of view, the estimates are very similar and there are no endogeneity issues.
} 
when one additional car is parked on the street for one hour, 3.6 drivers will have attempted to park their cars at the same location but are not able to do so and thus end up searching for parking. This translates into a marginal external cruising cost of about 1.2 Liras per hour of parking under plausible assumptions. This external cost is quite substantial. It is about 60 percent of the marginal parking fee that drivers face after parking for one hour and 15 percent of the hourly wage in Istanbul. For the average parking duration of two hours, this translates into an external cruising cost that even exceeds a trip's external congestion cost. Furthermore, as we ignore other disadvantages of excess parking demand (e.g., inefficient sorting, car driving externalities, etc.), increasing parking fees (at least by 1.2 Liras) would surely increase welfare.

Our work substantiates the claim that smart parking policy substantially improves societal welfare. Our results indicate that the externalities due to cruising for parking far exceed those related to traffic congestion for city-center shopping trips in Istanbul. Applying our methodology to other places where cruising is common, including North American cities, sets out a future research agenda that will quantify the welfare loss caused by underpriced parking.

\section{References}

Abrantes, P.A.L., M.R. Wardman (2011), Meta-analysis of UK values of travel time: An update. Transportation Research Part A, 45, 1-17.

Anderson, M. (2014), Subways, strikes and slowdowns: the impacts of public transit on traffic congestion. American Economic Review, 104, 2763-2796.

Anderson, M., M. Auffhammer (2014), Pounds that kill: the external costs of vehicle weight. Review of Economic Studies, 81, 535-571.

Anderson, S.P., A. de Palma (2004), The economics of pricing parking. Journal of Urban Economics, 55, 1-20. 
Anderson, S.P., A. de Palma (2007), Parking in the city. Papers in Regional Science, 86, 621-632.

Arnott, R., E. Inci (2006), An integrated model of downtown parking and traffic congestion. Journal of Urban Economics, 60, 418-442.

Arnott, R., E. Inci (2010), The stability of downtown parking and traffic congestion. Journal of Urban Economics, 68, 260-276.

Arnott, R., E. Inci, J. Rowse (2015), Downtown curbside parking capacity. Journal of Urban Economics, 86, 83-97.

Arnott, R., J. Rowse (2009), Downtown parking in auto city. Regional Science and Urban Economics, 39, 1-14.

Bakis, O., E. Inci, O. Senturk, (2015), Unbundling curbside parking costs from house prices and rents. mimeo. Sabanci University.

Basso, L., H. Silva, (2014), Efficiency and substitutability of transit subsidies and other urban transport policies. American Economic Journal: Economic Policy, 6, 1-33.

Belloche, S. (2015), On-street parking search time modelling and validation with survey-based data. Transportation Research Procedia, 6, 313-324.

Calthrop, E., S. Proost (2006), Regulating on-street parking. Regional Science and Urban Economics, 36, 29-48.

Chen, Y., A. Whalley (2012), Green infrastructure: The effects of urban rail transit on air quality. American Economic Journal: Economic Policy, 4, 58-97.

De Borger, B., B. Wuyts, (2011). The tax treatment of company cars, commuting and optimal congestion taxes. Transportation Research Part B: Methodological, 45, 1527-1544.

Duranton, G., M. Turner (2011), The fundamental law of road congestion: Evidence from US cities. American Economic Review, 101, 2616-2652. 
Inci, E., R. Lindsey (2015). Garage and curbside parking competition with search congestion. Regional Science and Urban Economics, 54, 49-59.

Kelly, J.A., J.P. Clinch (2009), Temporal variance of revealed preference onstreet parking price elasticity. Transport Policy, 16, 193-199.

Koster, H.A., J.N. van Ommeren, P. Rietveld (2014), Agglomeration economies and productivity: a structural estimation approach using commercial rents, Economica, 81, 321, 63-85.

Lancaster, T. (1992), The Econometric Analysis of Transition Data. Cambridge University Press, Cambridge.

Levy, N., K. Martens, I. Benenson (2012), Exploring cruising using agent-based and analytical models of parking. Transportmetrica, 9, 773-797.

Parry, I, M. Walls, W. Harrington (2007), Automobile externalities and policies. Journal of Economic Literature, 373-399.

Parry, I., K. Small (2009), Should urban transit subsidies be reduced? American Economic Review, 99, 700-724.

Pissarides, C. A. (2000), Equilibrium Unemployment Theory, MIT Press, second edition, Cambridge.

Salomon, I. (1984), Toward a behavioural approach to city centre parking: the case of Jerusalem's CBD. Cities, 3, 200-208.

Schaller Consulting. (2006). Curbing cars: shopping, parking and pedestrian space in SoHo. http://transalt.org.

Shoup, D.C. (1999), The trouble with minimum parking requirements. Transportation Research Part A, 33, 549-574.

Shoup, D.C. (2005), The High Cost of Free Parking. American Planning Association, Chicago, IL.

Shoup, D.C. (2006), Cruising for parking. Transport Policy, 13, 479-486.

Shoup, D.C. (2007), Cruising for parking. Access, 30, 16-22. 
Small, K., C. Winston, J. Yan (2005). Uncovering the distribution of motorists' preferences for travel time and reliability. Econometrica, 73, 1367-1382.

Small, K., Verhoef, E. (2007). The Economics of Urban Transport. Routledge.

Transportation Alternatives (2007). No vacancy. Park Slope’s parking problem and how to fix it. http://transalt.org.

TurkStat (2013), Household Labor Force Survey 2013.

van Ommeren, J.N., D. Wentink, P. Rietveld (2012), Empirical evidence on cruising for parking. Transportation Research A, 46, 123-130.

Vickrey, W. (1954). The economizing of curb parking space, Traffic Engineering, 62-67 (reprinted in Journal of Urban Economics, 36, 42-65).

White, M. (2004), The “arms race” on American roads: the effect of sport utility vehicles and pickup trucks on traffic safety. Journal of Law and Economics, 47, 333-355.

Wooldridge, J.M. (2002), Econometric Analysis of Cross Section and Panel Data. MIT press, Cambridge. 


\section{Appendix}

(a)

Price jumps at 75, 135, and 195 minutes of parking (Table 2)

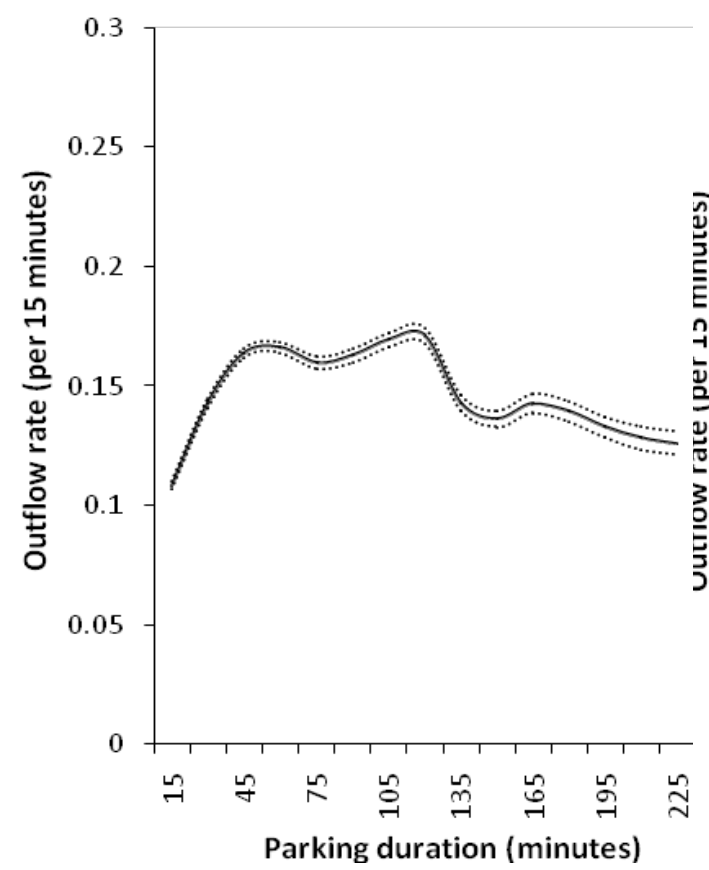

(b)

135 minutes of free parking (Turkcell)

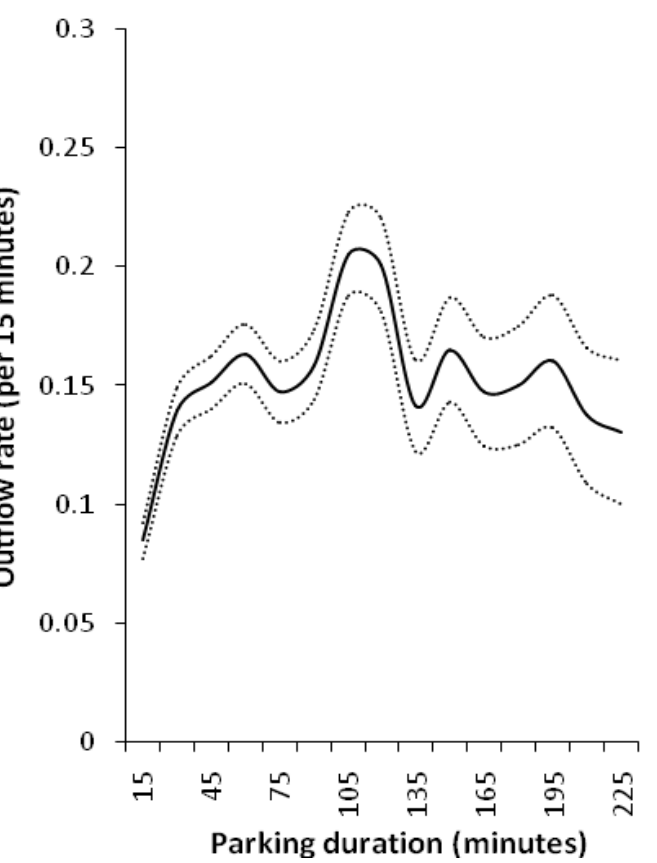

(c)

180 minutes of free parking (Press)

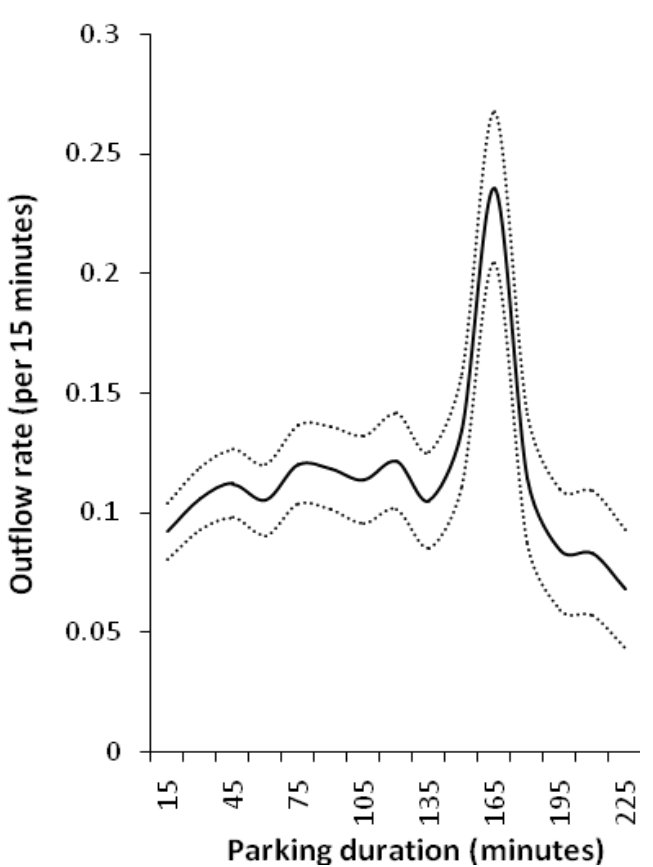

Figure 3: Outflow rate as a function of parking duration

Notes: Outflow rates per 15 minutes ( $y$-axis) are plotted against parking duration in minutes ( $x$-axis). Panels (a), (b), and (c) are based on 179,921, 5,466, and 2,488 observations, respectively. The bold curves represent the point estimations and the dotted curves the 95 percent confidence intervals. 